\title{
Activation of lymphocytes
}

\author{
R. J. V. PULVERTAFT AND ISOBEL PULVERTAFT 1 \\ From the Department of Pathology, Makerere University College, Kampala, Uganda
}

SYNOPSIS The technique involved in studying the activation of lymphocytes in the resting form, and their recognition as dividing and functional cells was studied, using phase contrast and agar as well as fluid culture. Standardization of technical methods was found to be essential, and the effect of variables was studied. Lymphocytes from human umbilical cord vein blood were found to be spontaneously activated. Infestation by microfilaria either diminished or entirely inhibited activation. The significance of lymphocytic cohesion was considered and the formation of colonies of activated lymphocytes on agar is described. The effects of non-human vertebrate lymphocytes and of human cells other than lymphocytes were studied. Spontaneous activation of abnormal lymphocytes was noted.

Blood grouping has been of such importance in ensuring compatibility in transfusion that it is inevitable that a search for an analogous laboratory test applicable to organ transplantation should be made. It has long been recognized that when a graft is rejected sections show dense infiltration with lymphocytes. When Schrek and Donnelly (1961) noted that segregated lymphocytes from two individuals suffered morphological changes when mixed, the significance, at first, was not appreciated. More recently, however, many workers have studied the phenomenon, in some cases specifically in relation to its possible importance in organ grafting (Bain, Vas, and Lowenstein, 1964; Gordon and Maclean, 1965; Kasakura, Shinpei, and Lowenstein, 1965).

These changes in the morphology of lymphocytes were studied initially on live cells, but later workers have used other methods. Staining of films is used, but obscures many significant features (e.g., motility, cytoplasmic granulation, etc.). Autoradiography using 'tracers' is an elegant technique, but unlikely to be applicable to clinical pathology owing to technical difficulties. Simple cell counts are employed, and may well prove the best test of reaction between individuals. However, marked morphological changes occur much earlier than cell division, which is often sparse. Up to the present only one method at a time is used by most workers and it is not proved that all are studying the same phenomenon.

In this communication a return is made to the

'Present address: Hedges, Stour Row, Dorset.

Received for publication 19 May 1967. original method of Schrek and Donnelly and the morphological and other changes readily observed in living cells following lymphocyte admixtures are alone considered. An attempt is made to outline the technical details necessary and observations on the behaviour of lymphocytes in normal and abnormal conditions are related.

\section{TECHNIQUE}

MATERIAL Blood samples were obtained by venepuncture from 150 healthy young blood donors, of Ugandan or Asian race; no European samples were tested except those from the authors, which were regularly used as controls.

In addition, 34 samples of venous blood from the umbilical cord were examined and 23 samples from various animals, including reptile, fish, and hen.

SEGREGATION OF LYMPHOCYTES Ideally samples should contain only lymphocytes but in practice it is never possible to ensure this. Red blood cells were always present in varying numbers.

Lymphocytes can be separated from heparinized blood, but the use of heparin is to be avoided as during later processing small fibrin clots often formed and vitiated experiments; moreover heparin for clinical use usually contains a preservative.

Defibrinated blood, obtained by shaking samples with glass beads, gives good results. Even a small clot in the final product, however, removes many lymphocytes.

The actual segregation was carried out by methods described by Coulson and Chalmers (1964). Blood was slowly rotated in boro-silicate tubes with wisps of glass wool for one hour at $37^{\circ} \mathrm{C}$. A $3 \%$ solution of gelatine (May and Baker) was made up in phosphate buffer saline $p \mathrm{H} 7 \cdot 2$. This must be prepared afresh daily. Stale 
gelatine produces a granular precipitate. Two other commercial samples of gelatine proved unsatisfactory.

Of this solution, $5 \mathrm{ml}$. was placed in a plastic measuring cylinder and $25 \mathrm{ml}$. of blood was added; the cylinder was placed in a water-bath at $37^{\circ} \mathrm{C}$. and left for 30 minutes. Bubbles which form at the surface must be broken, as these hold up cells.

Sedimentation of red cells, polymorphs, and monocytes is rapid. The supernatant fluid contains most of the lymphocytes but also some eosinophils, polymorphs, and red blood cells. Many of these are removed by centrifugation at 500 r.p.m. for two minutes. This deposit is discarded and the supernatant again spun at 2,500 r.p.m. for five minutes.

The deposit is suspended in culture medium. This, of course, must not contain any cells. The serum used, at $20 \%$ concentration, was obtained from Ugandans and Asians. It was centrifuged at high speed and filtered; before use it was frozen at $-20^{\circ} \mathrm{C}$. No cells were found on examination.

The diluent was 199 (Glaxo), containing penicillin and streptomycin, and neomycin and nystatin were added. It should be noted that this complex medium contains four antibiotics and many other constituents to which an individual may be sensitized; and it is known that lymphocytes cultured with a reagent to which the donor is sensitized may be activated. Hence until entirely synthetic media are evolved 'false positive' reactions, though few, are inevitable.

The lymphocytes were counted, and diluted until each donor's cells equalled 2,000 per c.mm. This figure is not critical but as in all forms of tissue culture there is an upper and a lower limit consistent with efficiency.

CULTURE CHAMBERS As in all forms of tissue culture a gas-tight seal is essential. Our chambers were cylindrical vials of boro-silicate glass measuring $1 \mathrm{~cm} . \times 4.5 \mathrm{~cm}$., to which $3 \mathrm{ml}$. of cell suspensions was added. The vials were cultured statically and upright for six days. These details are very important. For example, if the vials are rotated practically no morphological changes are seen in mixed lymphocytes. Almost all leucocytes and red blood cells sink to the bottom of culture chambers, and lymphocytes do not adhere to glass and thus do not climb the sides. Hence, although the total number of cells and the number per c.mm. may not be varied, if a culture is made in a conical container the cells are too crowded to survive and all die quickly. Conversely if the container was a wide plastic ring, no activation occurred in mixed cultures; as will be shown, cell cohesion appears to be an essential requirement; controls in both cases were activated.

\section{RESULTS}

Tests were made of 150 human normal blood samples. In 64 cases lymphocytes from two donors were mixed, and in 56 activation was found. In eight cases there was no activation; this was due to $\mathrm{CO}_{2}$ loss, to stale gelatine, or to fibrin clots; no technically successful culture was negative. In most cases the cultures were duplicated.
The phenomenon of activation as seen morphologically will be discussed later. Here it may be stated that 'activation' implies that practically all the lymphocytes are affected by the gross and very obvious changes. The effect is not in any way graded when equal numbers of lymphocytes from any two individuals are added; and no distinction was seen when an individual's lymphocytes were grown with preparations from two or more other individuals.

It follows that simple admixtures of equal numbers of lymphocytes from any two individuals (other than uniovular twins) cannot be used as a test for graft or cell compatability as it is always followed by lymphocyte activation and is not graded or quantitative.

In all cases controls were set up; and in only one case did a control give a positive result. In this case, in which several cultures were set up, all the lymphocytes were 'activated'. The donor was clinically a normal Ugandan adult male.

THE PHENOMENON OF ACTIVATION: PHASE CONTRAST This was studied by continuous observation of cultures of lymphocytes on agar-coated slides at $37^{\circ} \mathrm{C}$.

When lymphocytes from one individual alone are studied they are at first spherical and on warming move sluggishly with their characteristic gait. When they touch each other they never cohere. They enlarge slightly but do not vary from their original morphology, showing very few cytoplasmic organoids and a homogeneously dark nucleus without nucleoli (Fig. 1).

The average diameter of the spherical cell is $6 \mu$. They never show mitosis.

When mixed lymphocytes are studied the first difference seen is cohesion or agglutination. The spherical cells are kept in motion at first by gravitation and convection and when two cells make contact they never separate. On warming, and becoming motile, they move towards each other and towards the groups already formed. Thus within twelve hours in the cultures of a single individual's cells these are widely scattered; and those of two individuals mixed are almost all in three-dimensional clumps (Fig. 2).

In 48 hours small colonies of circular outline form with mixed lymphocytes and in six days they are upwards of $3 \mathrm{~mm}$. in character. If many red cells are present they are red; if not they are white. Lymphocytes from one individual (other than from cord blood) never form colonies (Fig. 3).

Morphological changes in mixed lymphocytes occur as early as 24 hours after explantation. The first change is the appearance of a large nucleolus. The whole cell enlarges and the nucleus becomes mottled; granules and large filamentous mito- 


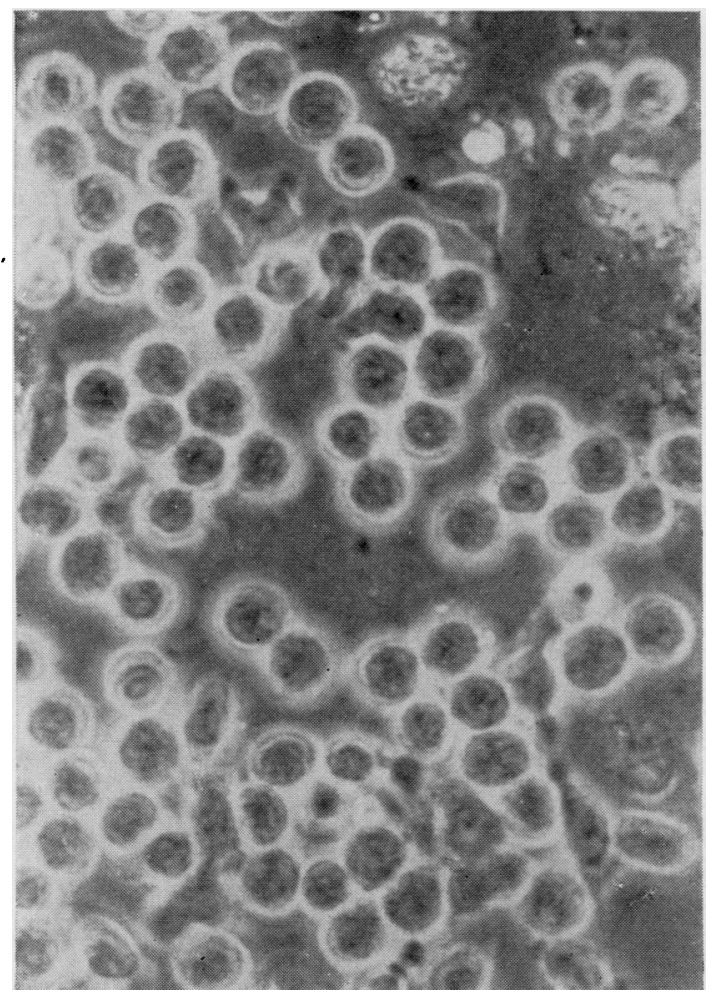

FIG. 1.

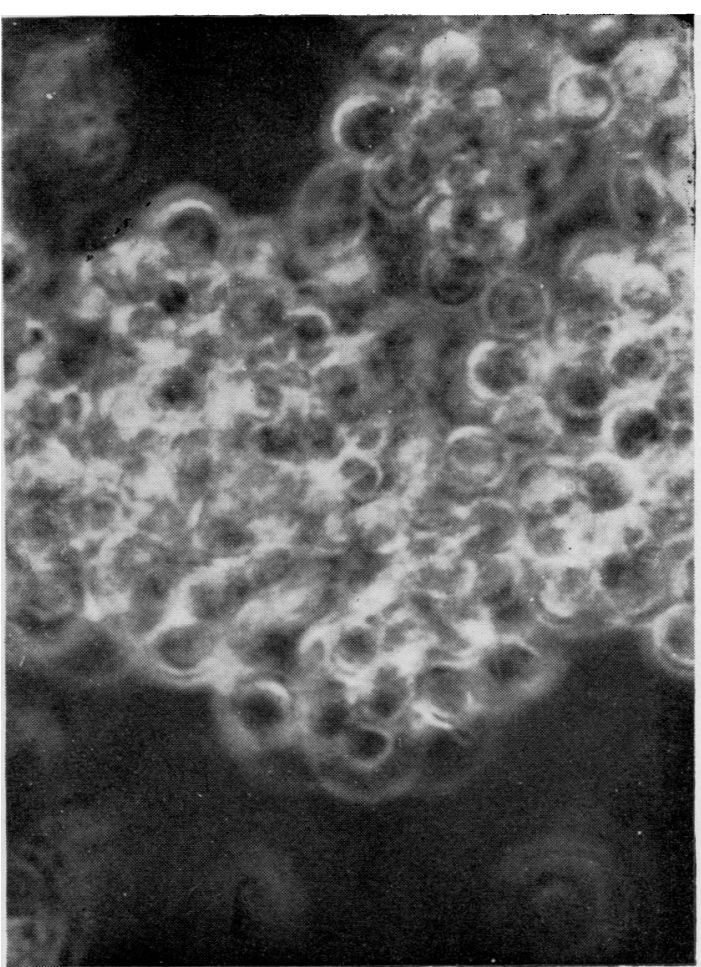

FIG. 2 .

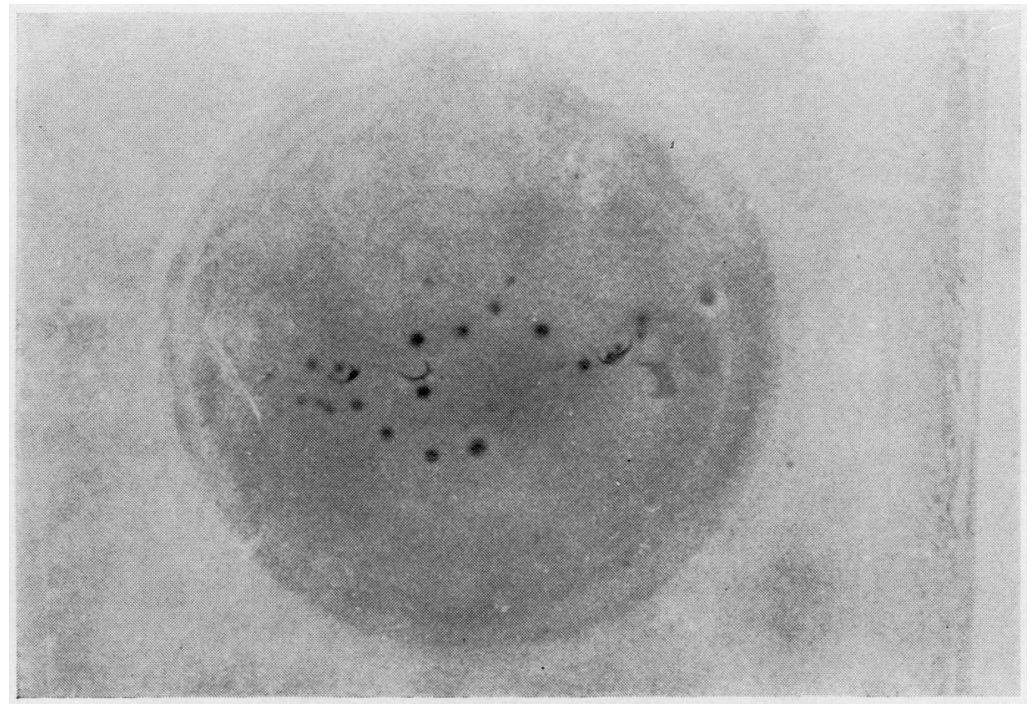

All photographs except Fig. 3 were taken at $37^{\circ} \mathrm{C}$. by phase, $\times 1,500$ The cells illustrated are from unmixed cultures of umbilical cord lymphocytes but identical changes occur in mixed cultures.

FIG. 1. Lymphocytes on inoculation.

FG. 2. Lymphocytic agglutination after 96 hours.

FIG. 3. Colony formation by cord lymphocytes on agar $\times 3$.

FIG. 3 . 


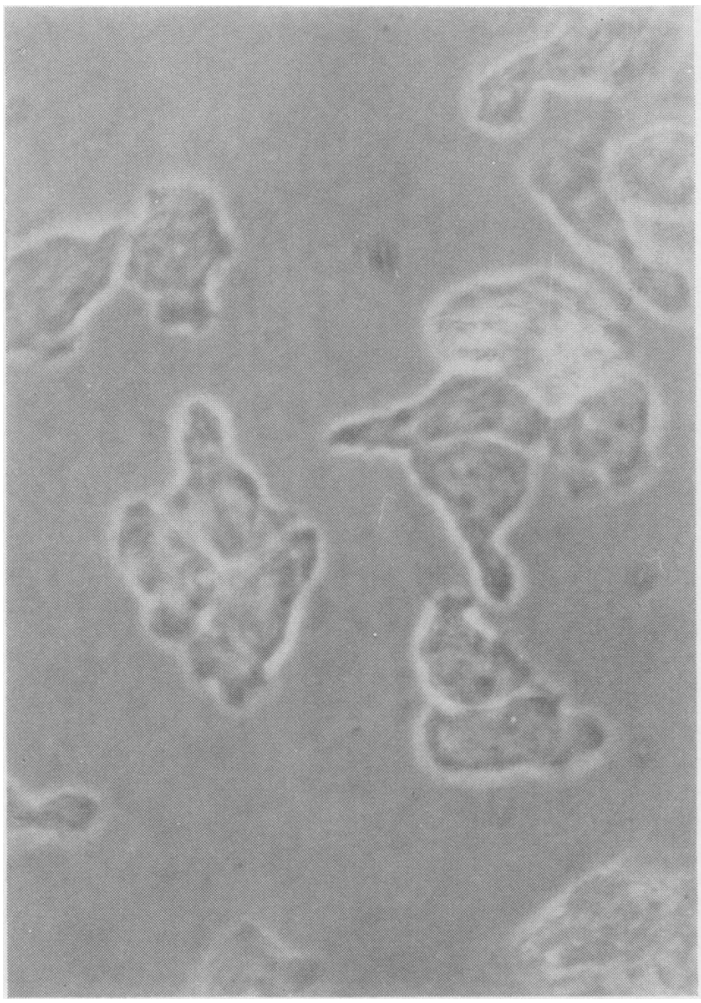

FIG. 4.

chondria appear in the ctyoplasm. Eventually after five days the whole cell shows five times its original diameter. Pseudopodia, instead of being blunt and bulbous, are pointed. Mitosis occurs in most, but not all, cases. Motility ceases (Fig. 4-8).

In fluid cultures colonies develop at the bottom of containers. Attempts to subculture or to maintain cultures have failed. No effect, morphological or otherwise, is seen following the addition of phytohaemagglutinin to activated cultures of mixed lymphocytes and the end-cell following mixed culture is indistinguishable from the cell found after phytohaemagglutinin stimulation.

According to Gordon and Maclean and to Kasakura and Lowenstein (loc. cit), the culture medium in which lymphocytes from one individual have been grown stimulates lymphocytes from another individual, causing great multiplication. We, however, have found no morphological changes in similar circumstances.

Single source lymphocyte cultures were grown for six days and the medium removed with a pipette with an up-turned point. This fluid was centrifugalized and, surprisingly, showed an obvious deposit of cells.

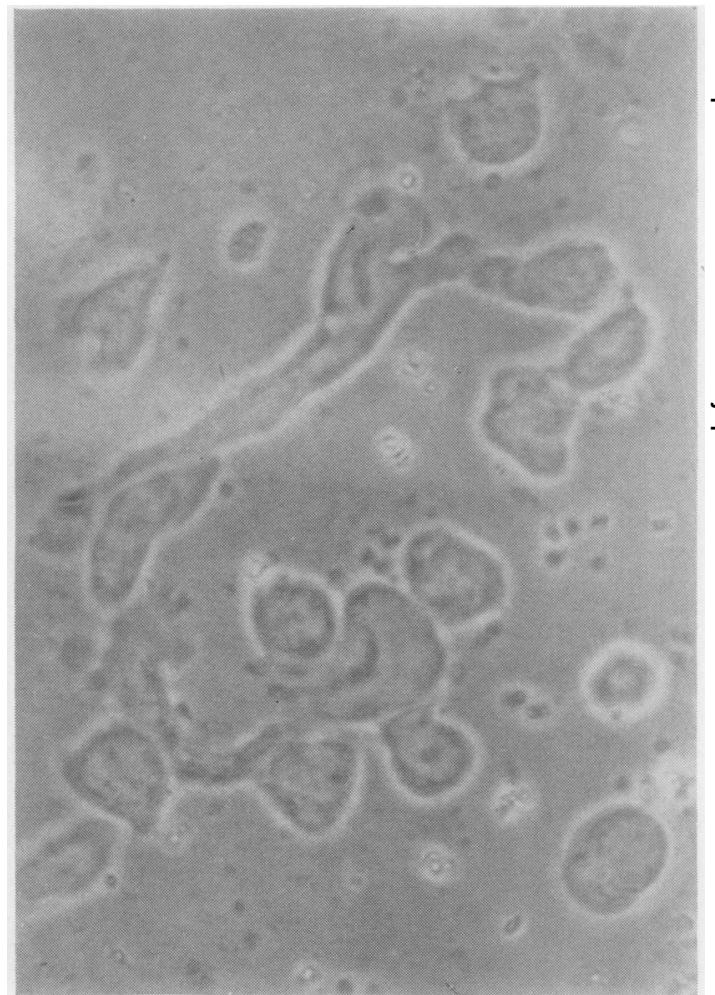

FIG. 5 .

The supernatant fluid was removed, and again spun, this time without yielding a deposit.

Lymphocytes from another individual were explanted in fresh medium to give a concentration of 4,000 cells per c.mm. Three $\mathrm{ml}$. of these cells was centrifuged and the deposit re-suspended in the medium in which other lymphocytes had grown. Control suspensions were mixed with another individual's lymphocytes and always showed characteristic activation in six days. In contrast the test lymphocytes never showed any morphological changes.

In addition to single source lymphocyte culture $\sigma$ media, medium in which cells from two individuals $N$ have been grown and shown activation, and medium in which cord blood lymphocytes had been grown 0 were used. No morphological change was ever found.

In a previous communication using cultures separated by millipore filters, activation was stated $\stackrel{\oplus}{?}$ to have been found (Pulvertaft and Pulvertaft, 1966). This, however, was an erroneous result, due in all probability to admixture of small amounts of other lymphocytes since the lateral apertures were close together. When this was prevented by the use of 


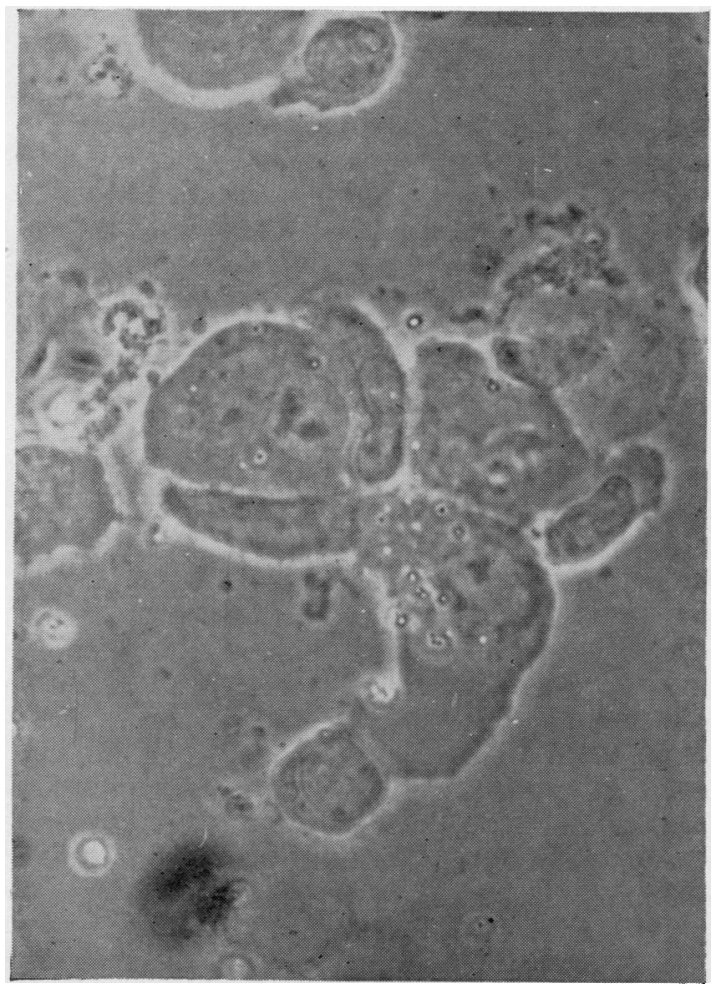

FIG. 6 .

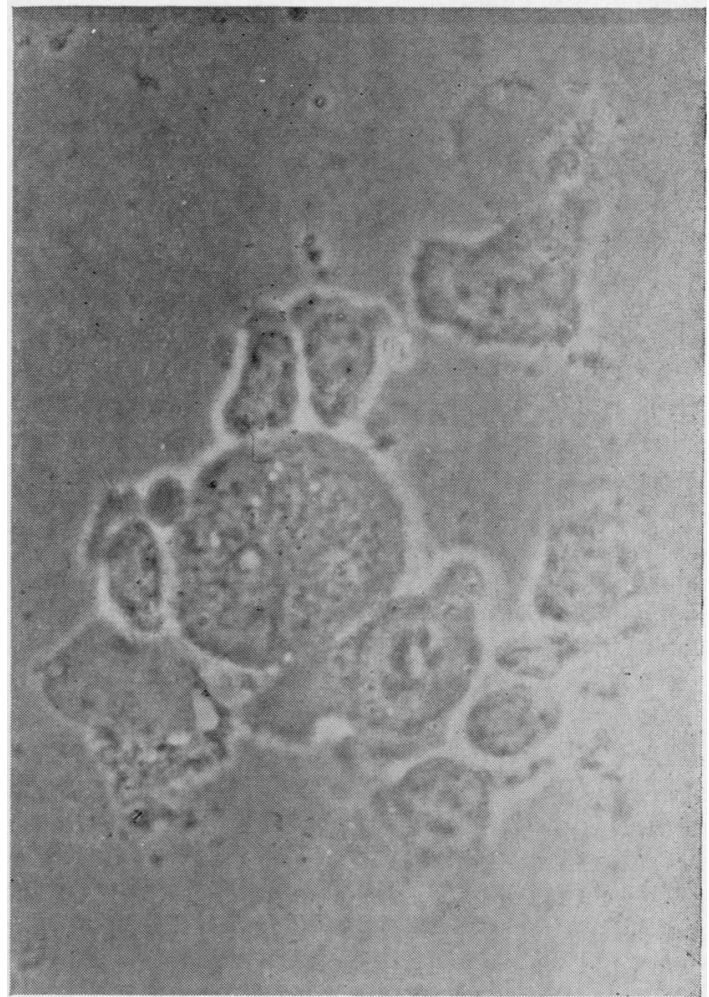

FIG. 7.

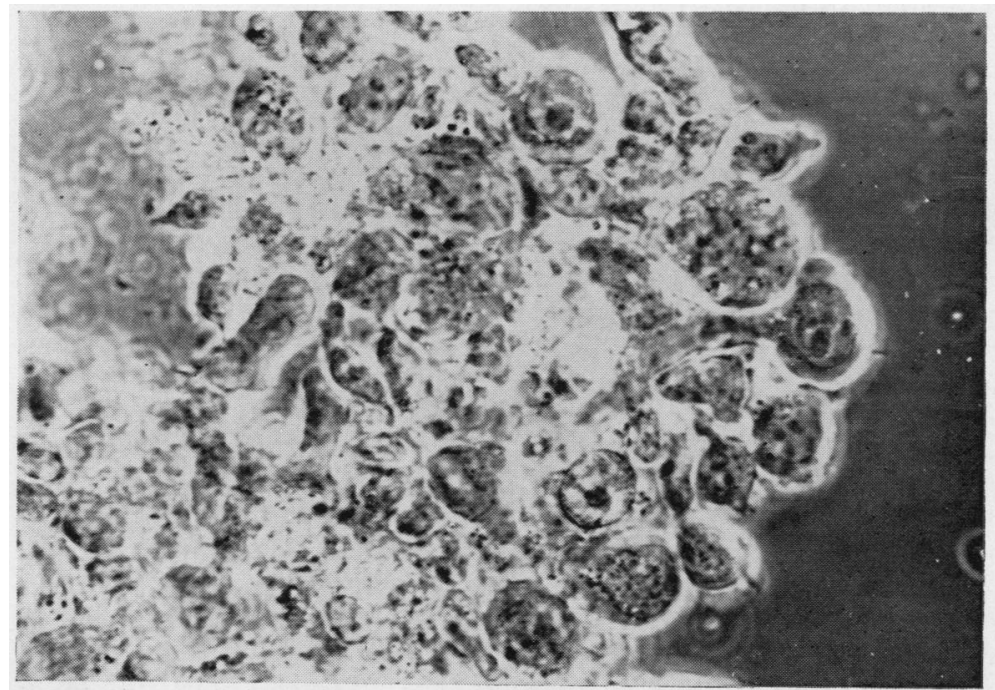

FIG. 4. Lymphocytes (18-hr. culture).

FIGS. 5-7. Activated lymphocytes (three to five days).

FIG. 8. Colony of agglutinated and activated lymphocytes (five days). 
chambers with widely separated apertures no activation was found.

INACTIVITY OF CELLS OTHER THAN LYMPHOCYTES Monolayers were prepared from the kidney of a grey monkey, from two cases of human thyroid enlargements, and from a malignant melanoma. Segregated lymphocytes were added to these cultures from several individuals: the cultures were examined at $37^{\circ} \mathrm{C}$. by phase contrast. The lymphocytes remained alive; they did not change their appearance or multiply.

ACTIVITY OF NON-HUMAN VERTEBRATE LYMPHOCYTES Heparinized blood was obtained from four species of monkey, and from rat, rabbit, and hamster. In all cases, when mixed with human lymphocytes, their segregated lymphocytes gave full activation. Blood was collected with heparin from a crocodile (shot in the head) and from an anaesthetized python, lung fish, and hen. Small cells segregated from these specimens by the technique used for mammalian blood and mixtures were incubated at $37^{\circ} \mathrm{C}$. in the standard medium with human lymphocytes. No activation occurred.

These animal experiments were performed during the early stages of our investigations and before technique was standardized.

LYMPHOCYTES FROM VENOUS UMBILICAL CORD BLOOD By venepuncture up to $25 \mathrm{ml}$. of blood can be obtained from the umbilical cord vein, if punctured immediately after ligature of the cord. and before the placenta is expelled. Delay in puncture involves the extraction of a much smaller volume. Although blood is often collected by section and drainage of the cord this is to be avoided owing to the danger of mixture of maternal blood and of tissue elements from the cord itself.

It was found that segregated lymphocytes from such specimens all showed activation in all specimens tested without addition of any other cells. The technique was identical; 4,000 lymphocytes per c.mm. were cultured for six days in a $3 \mathrm{ml}$. volume.

They were, indeed, by far the most active cells tested. It has been stated that culture of too few cells in mixed cultures leads to failure to produce activation. But in the case of cord blood, it was found that serial dilution showed complete activation down to a concentration of 150 cells per c.mm., the lowest tested; below this concentration it is difficult to observe the cells.

When first examined all the cells were normal, highly motile, small lymphocytes. Changes were first noted in $\mathbf{4 8}$ hours and were complete in six days.

Maternal blood was collected immediately after the cord blood. The lymphocytes showed no activation after six days.

Up to the present, no information is available as to the behaviour of lymphocytes from premature infants, or from infants 6 days or more old.

THE INFLUENCE OF FILARIAL INFESTATION Microfilaria perstans is exceedingly common in Uganda. It is found not only in the blood, but in pericardial, pleural, and peritoneal exudates and also in preparations of neoplasms such as Burkitt's tumour and in non-malignant enlargement of thyroid. Methods of concentrating lymphocytes also concentrate microfilaria, which are found in the supernatant fluid when red cells are sedimented and in the deposit when the supernatant fluid is centrifugalized. Their vigorous movement renders them easily visible; and they remain alive and motile for at least a fortnight. Eosinophils have been noted to become adherent to them, covering them almost completely.

They were commonly found in blood from volunteer blood donors, so that all serum for tissue culture had to be filtered. However, their presence in transfusion in the tropics is not important; they have to pass through their normal vector in order to become viable in the human host, according to authority.

Unfortunately, they were often present in blood collected for experiments with lymphocytes. It was found that when they were present, even in small numbers, activation of lymphocytes either did not occur at all, or if it did, was very poorly demonstrable with a mixture of another donor's cells. When lymphocytes from a donor were cultured with his own microfilaria alone, there was no activation at all. Cord blood never showed microfilaria, even when the mother was heavily infested. Eosinophils were, however, common in cord blood, sometimes in great numbers.

Non-activation of mixed lymphocytes in the presence of microfilaria may possibly be due to utilization of growth factors by the parasite. The lymphocytes, however, remain motile and apparently normal in their presence at least for 14 days. The violent agitation caused by their movements may prevent lymphocytic cohesion, which, as noted elsewhere, is a marked feature in activation.

The non-activation of lymphocytes from an infested donor is anomalous. The antigen, the microfilaria, is by definition present: lymphocytes in the presence of an antigen to which a donor has been exposed commonly are activated.

Another interesting possibility should be considered. Microfilaria have, by definition, come to terms with their host and, although they provoke a profound eosinophilia, obviously suffer no harm 
from host antibodies. In the case of Perstans infestation, the only one which we encountered in Uganda, the host himself, so far as is known, is in no way discomfited.

It is to be noted that, when lymphocytes from a subject with Perstans microfilaria are added to those of a normal subject, in most cases neither group of lymphocytes is activated. It is possible that in Perstans infestation a mechanism has been developed which specifically inhibits activation, and that without this mechanism the microfilaria could not survive in the blood.

The expert committee on filariasis of the World Health Organisation (Geneva, 1962) suggested that research on immunochemistry of filarial infections should be prosecuted and search for antibodies in old chronic human infections should also be conducted. It does not mention any work on immune reactions in filariasis.

We have performed only one experiment to see whether a child's red cells heavily infected with Pl.falciparum would induce activation of lymphocytes from an adult recently recovered from a similar acute infection. In fact, no activation occurred; it is obvious, however, that the experiment must be repeated many times before any valid opinion can be expressed.

TITRATION OF INDIVIDUAL A'S CELLS AGAINST THOSE OF INDIVIDUAL B The standard technique involved the culture of cells in cylindrical vials, $1 \mathrm{~cm}$. in diameter, the volume being kept constant at $3 \mathrm{ml}$., and the total number of cells at 12 million.

If the two individuals' cells are mixed in equal numbers, i.e., $1.5 \mathrm{ml}$. of each containing 6 million cells, activation normally occurs in six days, and in this way it is not possible to determine whether the cells of one individual induce more activation than those of another. In our experiments the contents of vials are inverted, and transferred to centrifuge tubes; after centrifugalization all the deposit was taken up with a pipette, and transferred to a microscope slide, care being taken not to disperse aggregates by raising the deposit carelessly. Normally (unless, for example, microfilaria are present or $\mathrm{CO}_{2}$ has escaped from ill-stoppered vials) aggregates of hundreds or thousands of cells are seen, the great majority being the large, activated lymphocytes.

One method of distinguishing the activation potency of an individual's lymphocytes is to perform daily counts on the mixed cultures, which in itself involves dispersal of aggregates with possible modification of the final result, as we have found when vials are rolled during culture. A second method is to keep the total number of cells of individual A constant, and to add diminishing numbers of individual B's cells. Strictly speaking, in order to be sure which individual's cells are the most active, the experiment should then be performed by keeping B's cells constant and varying those of A.

In practice the volume of blood which can properly be taken from volunteers, who in our cases were nearly all blood donors offering normal contributions for transfusion, is an additional $20 \mathrm{ml}$.; and this volume will not permit, as a rule, of more than six experiments on any one specimen, if each vial is to contain 12 million lymphocytes from one individual alone. It is not possible therefore to consider in any one experiment many variables.

As examples of the kind of results which may be obtained, the following experiments may be cited:

\begin{tabular}{|c|c|c|c|c|c|}
\hline & & TA & BLE & & \\
\hline & B Cells & B Cells & B Cells & B Cells & B Cells \\
\hline & 400,000 & 40,000 & 4,000 & 400 & 40 \\
\hline $\begin{array}{l}\text { A cells } \\
12 \\
\text { million }\end{array}$ & $\begin{array}{l}\text { Activation } \\
++ \\
\text { C cells } \\
400,000\end{array}$ & $\begin{array}{l}\text { Negative } \\
\text { C cells } \\
40,000\end{array}$ & $\begin{array}{l}\text { Negative } \\
\text { C cells } \\
4,000\end{array}$ & $\begin{array}{l}+++ \\
C \text { cells } \\
\mathbf{4 0 0}\end{array}$ & $\begin{array}{l}\text { Negative } \\
\mathrm{C} \text { cells } \\
40\end{array}$ \\
\hline $\begin{array}{l}\text { B cells } \\
12 \\
\text { million }\end{array}$ & ++++ & Negative & Negative & Negative & Negative \\
\hline & $\begin{array}{l}\text { A cells } \\
400,000\end{array}$ & $\begin{array}{l}\text { A cells } \\
40,000\end{array}$ & $\begin{array}{l}\text { A cells } \\
4,000\end{array}$ & $\begin{array}{l}\text { A cells } \\
400\end{array}$ & $\begin{array}{l}\text { A cells } \\
40\end{array}$ \\
\hline $\begin{array}{l}\mathrm{C} \text { cells } \\
12 \\
\text { million }\end{array}$ & Not done & +++ & +++ & +++ & ++ \\
\hline
\end{tabular}

The results demonstrate clearly that serial dilution of cells does not necessarily give a clear-cut result; in the case of A cells against $B$ cells after two negative results a strong positive result was given with only 400 cells.

However, in two cases 400,000 cells mixed with 12 million cells induced marked activation. A cells were activated by $C$ cells at all concentrations tested, even when a nominal number of only 40 cells was added. The errors of dilution and of counting are of course considerable.

THE RELATIONSHIP OF ACTIVATED LYMPHOCYTES TO MALIGNANT LYMPHOMAS It has been pointed out that the activated lymphocyte has certain points of similarity to the cells of Burkitt's lymphoma (Pulvertaft, 1964). The formation of cellular aggregates in particular is a significant common feature.

However, the process of activation is one of continuous development; it begins with the appearance of a nucleolus; it continues with the development of granules and gross enlargement; it concludes with mitosis and the development of the property of staining with pyronin. 
We have made a study of the cells of malignant lymphomas in London, Nigeria, and Uganda for many years, using the same methods of examination, i.e., agar culture and phase examination of living cells. It is possible to find, in the series of changes occurring in the activated lymphocyte, resemblances with all the cells of malignant lymphomata, however named, in each new annual reclassification.

A cytologist presented with a fully activated culture of normal lymphocytes would find it difficult to distinguish it from a culture, for example, of a 'reticulosarcoma'.

It may be that lymphocytes can be 'activated' either by an immune process, or a carcinogenic stimulus, and that morphologically there is difficulty in distinguishing them. One marked distinction is that the malignant lymphocyte can be cultivated continuously in vitro; we, at least, have failed to do so with the non-malignant cell.

'Activated' cells have, in general, a family resemblance, differing chiefly in size from each other. But sometimes quite different cells are seen with a much darker cytoplasm and nucleus. Indeed, on one occasion a typical small lymphocyte, from cord blood, was seen in mitosis. It appears therefore that activated lymphocytes can develop along more than one channel and that the most usual type of development studied here is dependent on the environmental conditions occasioned by the cultural techniques.

Nucleated red cells are present in small numbers in cord blood, but do not multiply; myelocytes are present in small numbers; mitosis has been seen.

ABNORMAL LYMPHOCYTES Since this communication deals with the behaviour in vitro of normal lymphocytes, consideration of the culture of cells from disorders of the haemopoietic system is not in general relevant.

There are, however, a few considerations which should be kept in mind. Segregated leukaemia cells, both of the myeloid and lymphoid series, survive readily in fluid culture medium for several weeks, and a number of cell lines, both of human and animal leukaemia, are maintained. We have studied many primary cultures, although to date none has been established by us as a cell line. Reference will be made only to leukaemia of the lymphoid series.

In Uganda 'lymphatic leukaemia' is regularly encountered, and in our experience the commonest cell type, both in children and in adults, is a small lymphocyte differing when first isolated little if at all from a healthy lymphocyte, when studied by phase contrast at $37^{\circ} \mathrm{C}$. When grown in fluid culture, however, the lymphocytes of normal appearances die out, and are seen as ghosts.

Bizarre forms, often in mitosis, appear within a few days, and these clearly resemble activated lymphocytes as above described.

One case deserves notice in more detail. A young man of 23 complained of weakness and no physical signs were found. His blood showed a gross anaemia, with 3,000 leucocytes per c.mm., $90 \%$ of which were normal small lymphocytes. His bone marrow showed $80 \%$ small lymphocytes, with $10 \%$ 'blast' cells. The blood lymphocytes were segregated, and cultured in fluid medium for six days by the standard technique. At the end of that time only very large 'clumps' of activated lymphocytes were present, and the original small lymphocytes were no longer to be seen. The diagnosis in this case was 'aleukaemic leukaemia'.

Although a single case can be no more than suggestive, the study of segregated lymphocytes in such conditions by culture may prove valuable. There are some disorders as yet not classified, in which gross splenomegaly is a presenting symptom; the culture of blood lymphocytes in these cases of tropical 'big spleen disease' should be considered. We have seen two cases with this diagnosis which terminated as malignant reticulosis, diagnosed histologically as 'stem cell sarcoma'.

\section{DISCUSSION}

In this paper the word 'activation' is used to denote the changes found in lymphocytes instead of the conventional word 'transformation' which is used in many senses. It appears first in pathology in the first paper in the first number of the Journal of Pathology and Bacteriology where Virchow used it in relation to changes seen in malignant cells. When tissue culture was introduced, it was used to cover all developments seen in explanted cells; and when 'cell lines', such as Hela cells, were established they were known as 'transformed' cells. These have all chromosome abnormalities; the other categories have not, or not necessarily.

The word itself was first used in relation to the drama, in the Elizabethan period, to allude to the alteration in an actor's appearance when he changes his costume. Hence its use as a polite synonym for a wig in Victorian times. It is used, of course, in every science as in the electrical transformer. Presumably the word implies the preservation of essential individuality while 'mutation' implies a change of individuality. In our present state of ignorance 'activation', which implies merely that the lymphocyte acquires new properties, is preferable.

The activation of lymphocytes has been achieved in many ways since the influence of phytohaemagglutinin was discovered, and there is still no agreement as to the essential nature of the phenomenon. 
The end result seems always to be the same, namely, the conversion of a dormant cell to one of great activity, and all the evidence points to the belief that one of these forms of activity is the production of antibodies.

Why lymphocytes from one person should stimulate those of another, or more probably why they should reciprocally react, is not at present clear. There is at present no evidence that any other cell has this property in vitro. In the living animal the rejection of grafts shows that a host reaction takes place, involving any type of cell whatsoever. But so universally is the lymphocyte distributed in every organ that it is quite impossible to graft a piece of tissue without also introducing lymphocytes. If our experiments are confirmed, very few lymphocytes indeed can activate an enormously larger number of alien cells.

There is massive evidence that lymphocytic activation is harmless to the individual; indeed, everything points to its being essentially beneficial. Every transfusion involves the transfer of great numbers of lymphocytes. We have not concluded work on post-transfusion lymphocyte behaviour; stored blood six days after transfusion caused no activation of lymphocytes in the recipient. What happens if fresh blood is used, and the recipient's lymphocytes collected while the transfusion is still running has yet to be determined; in one case this gave a positive result.

The behaviour of cord blood lymphocytes was unexpected; the segregated cells were very active indeed, and divided even in the smallest number which could be examined. Cord serum itself did not activate adult lymphocytes; and cord lymphocytes were activated in the presence of human adult serum. Maternal lymphocytes simultaneously collected did not show activation spontaneously.

Until proof to the contrary is obtained, the most likely suggestion is that during parturition and separation of the placenta maternal blood escapes into the foetal circulation. This is in fact known to occur. Desai and Creger (1963) collected maternal blood, and labelled the leucocytes with atebrine; just before parturition they were re-injected into the mother, and when born, the infant's blood was examined for fluorescence. Some labelled cells were found but in such small numbers that it was thought that they could not have any effect on the infant.

However, since in our experiments very few lymphocytes indeed evoked a profound reaction, this opinion must be reconsidered. It could have no effect greater than the transfusion of maternalblood, which is often performed with advantage. It could not cause 'runting' if the lymphocytic transfer is during parturition, since only the young foetus is affected in this way. Certainly the most likely time for transfer is when the placenta is separated. It is possible that accidental and abnormal separation and transfer may occur earlier in pregnancy, and that this might occasion foetal abnormality, but this is pure conjecture.

Our observations do support the belief that the volume of maternal blood transferred is small, since even when the mother's blood is heavily infested with microfilaria, there are none in the cord blood.

Attention has been directed to the observation that more than one morphological entity may proliferate in cultures of activated and segregated lymphocytes. In one case four types were found: (1) the granular predominant type, $30 \mu$ in diameter; (2) a much darker non-granular cell, $30 \mu$ in diameter (Fig. 9); (3) a small cell, $6 \mu$ in diameter, indistinguishable from a small lymphocyte (Fig. 10); (4) myelocytes, segregated along with the lymphocytes. All were in active division. There is evidence that segregated lymphocytes may develop along more than one channel.

It is not known what the end result, in the body, of the activated cell is. On one occasion these cells were within a macrophage; this may be their normal destination. In vitro they disintegrate within a few weeks; but so do most adult mammalian explants.

The importance of studies on lymphocytic transformation or activation is great. First, the fact that one of the commonest mammalian cells was until recently believed to be an 'end' cell, with no known function, and is now known to be a resting cell with unlimited potentiality, is a major discovery. Secondly, it is hoped, with optimism, if up to the present without evidence, that its study in vitro may prove helpful in selecting donors for organ transplantation. Lastly, the basic problem of carcinogenesis is the nature of cell stimulation leading to unnatural multiplication, and any information about cell stimuli must take its place in the forefront of cancer research.

These discoveries are so recent that it would be uncharitable to suggest that divergence in technique makes it impossible to correlate results. If we compare an analogous biological test, the RidealWalker test, for antiseptic activity, we find that a standard broth culture medium, a standard platinum loop to measure the inoculum, pure phenol, and a stipulated crystallizing point, a standard culture of S.typhi and a rigid technical method are essential in order to reproduce the results. Indeed, any bacteriologist knows that duplicate results are often unobtainable. Even so, the test only gives the relative value of antiseptics under conditions in which, in fact they would never be used.

Until technique is standardized, the practical 


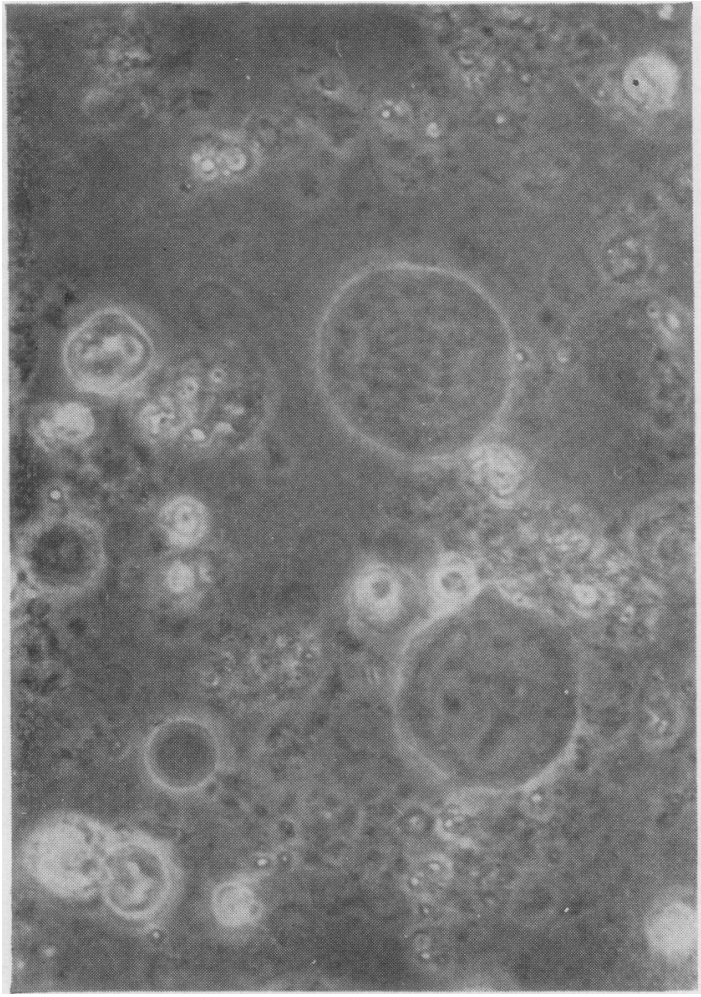

FIG. 9. 'Dark' cells ( five-day culture).

application of studies of lymphocytic behaviour will be impossible. There must be agreement in the first place on whether segregated lymphocytes or buffy coats containing all leucocytes are to be used. If lymphocytes alone are to be used, the method of segregation and the permissible numbers of other cells must be defined. There is no such thing as a preparation with lymphocytes alone. The nature of the culture medium must be defined; in fact this cannot at present be precisely achieved, as some animal serum must be used and no two sera are of identical composition. The shape of the container must be defined as the lymphocytes always settle to the bottom, where, if the area is sufficiently constricted, they cannot survive. The number of lymphocytes per c.mm. and the total volume of cell suspension must be defined, since these determine the thickness of the cell carpet. Certain preparations cannot be tested, e.g., those containing microfilaria. The duration of cell culture must be agreed; and if mixtures of cells from two individuals are studied the proportion of each individual's cells must be agreed. During culture, it must be agreed that containers are kept static or rotated; and if kept

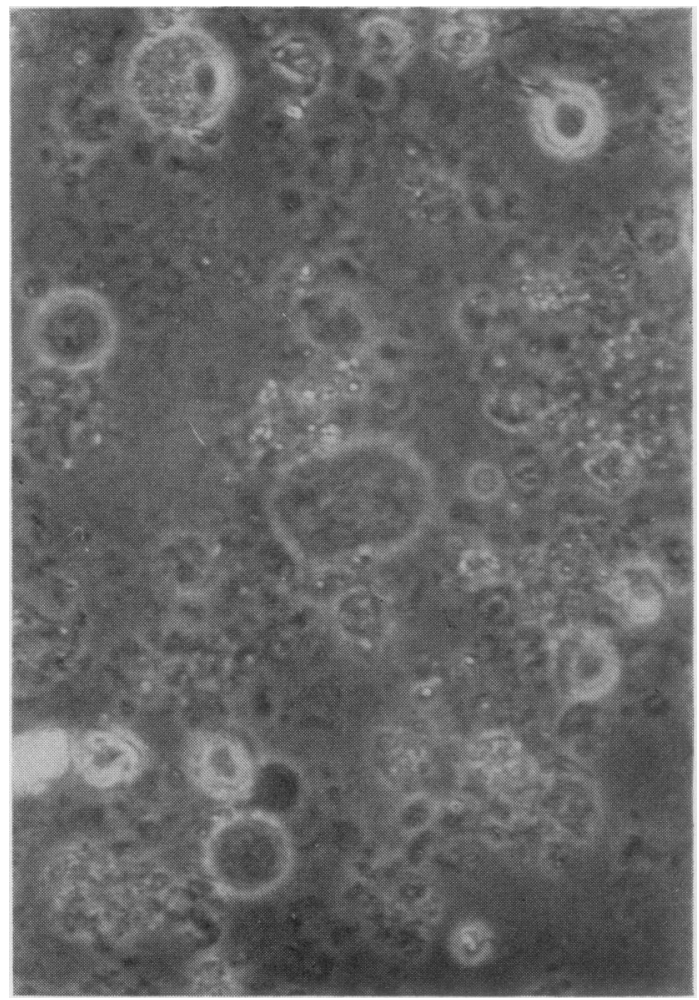

FIG. 10. Small lymphocyte in mitosis (five-day culture).

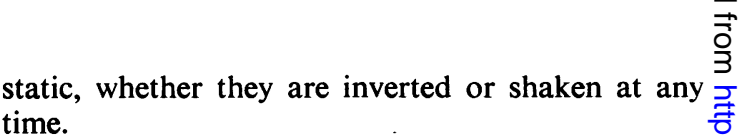

Finally, and most urgently, there must be agreement, if it is at all possible, what a 'transformed' or? 'activated' cell is. This will take a long time. We may 윽 recall that no cell is more frequently mentioned in papers on lymph node pathology than the 'reticulum cell'. Gall (1958), however, believed it to be a myth and illustrates 17 completely different 'reticulum 윽 cells' collected from authoritative literature. We have $>$ tried to define 'activated' cells by all the criteria we were able to employ. Even then two things are clear: N 'activation' involves a continuous series from the standard resting cell to the very large end result; $N$ and, secondly, completely different cells appear and $\mathrm{C}$ divide by our techniques in small numbers; but possibly by a varied technique they might pre- $\bullet$ dominate. The use of lymphocytic 'transformation' to select organ donors, however desirable and how-? ever eventually possible, is not at present a practical $\frac{0}{2}$ proposition.

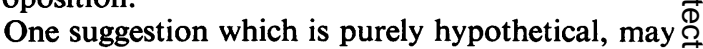
be made. Lymphocytes apparently react only with $\stackrel{\mathbb{\Omega}}{\Omega}$ lymphocytes: in our experiments other cell cultures 
had no effect. If graft reaction and rejection is related to lymphocyte activation the process may be initiated by the lymphocytes in the graft, and not by the epithelial or glandular cells. It is simple to kill lymphocytes without damaging other cells; Colcemid (Ciba), for example, is exceedingly effective. It would be of interest to test whether treating grafts with Colcemid to remove all donor lymphocytes has any effect on 'takes'.

This work was undertaken with the help of a full-time grant from the British Empire Cancer Campaign for Research.

Thanks are due to Professor M. S. R. Hutt for generous facilities and helpful advice, and to Professor R. R. Trussell and the staff of the obstetrical department of Mulago Hospital. We are particularly grateful to Sister Joyce Hoyes for her forbearance. Dr. Jean T. Holland, M.O. i/c Uganda Blood Transfusion service, and Dr. Elvira C. Arya gave essential advice and help in the collection of blood samples.
Our greatest debt is to the many blood donors who generously and anonymously contributed these samples.

Dr. M. C. Williams of the East African Virus Research Institute and Dr. T. M. Bell of the Imperial Cancer Research Fund gave much help in the collection of animal blood specimens.

The arduous and responsible task of preparing glassware and apparatus was performed by Mr. Herbert Wasswa, S/O Kyeyanga.

\section{REFERENCES}

Bain, B., Vas, M. R., and Lowenstein, L. (1964). Blood, 23, 108. Coulson, A. S., and Chalmers, D. G. (1964). Lancet, 1, 468.

Desai, R. G., and Creger, W. P. (1963). Blood, 21, 665.

Gall, E. A. (1958). Ann. N.Y. Acad. Sci., 73, 120.

Gordon, S., and Maclean, L. D. (1965). Nature (Lond.), 208, 795.

Kasakura, S., and Lowenstein, L. (1965). Ibid., 208, 794.

Pulvertaft, R. J. V. (1964). Lancet, 2, 552.

- (1965). J. clin. Path., 18, 261.

, and Pulvertaft, Isobel (1966). Lancet, 2, 892.

Schrek, R., and Donnelly, W. J. (1961). Blood, 18, 561. 